\title{
IUMRS Seeks Nominations for 2002 Sōmiya Award on International Collaboration
}

The International Union of Materials Research Societies (IUMRS) is seeking nominations for the annual Sōmiya Award, which recognizes research on real materials conducted by a research team whose members are drawn from at least two continents. The submission deadline is February 8, 2002.

Sōmiya Award recipients are selected by the IUMRS Commission on Awards. The recipients receive an award commemorating the occasion and free registration to the annual IUMRS International Conference, where they present their work. This year the conference will be held at the 8th International Conference on Electronic Materials (IUMRS-ICEM 2002), June 10-14, 2002, in Xian, China. Manuscript Central's security mechanism allows only the editor and reviewers assigned to a particular manuscript to view that manuscript. Reviewers, whose identities are kept confidential, only have access to the manuscript until their review is submitted.

The following criteria are used by the Commission on Awards for selection:

- The team to be honored must have collaborated across at least two continents (e.g., North America, Europe, Asia, Australia) some time during the last decade.

- The collaborative work must be of the highest quality and well recognized by the international materials community.

- The impact on technology or society is also a major factor.

IUMRS was established in 1991 as an international association of technical groups and societies that have an interest in promoting interdisciplinary materials research. The annual Sōmiya Award is named in honor of Shigeyuki Sōmiya, professor emeritus of the Tokyo Institute of Technology and later dean at Teikyo University of Science and Engineering. Sōmiya has received the MRS Medal and the Japanese Scientific Academic Award. Sōmiya spent his postgraduate years in the United States and embarked on a series of collaborative research and exchange visits in many countries, starting in 1969 with the U.S.-Japan Workshop in Ceramics. He also actively pursued joint work with colleagues in Europe and brought many international materials gatherings to Japan.

The 2001 Sōmiya Award for International Collaboration in Materials Research was awarded to an American-European research team led by Antonio Tomsia of Lawrence Berkeley National Laboratory for their investigation of graded bioactive coatings for medical implants and the potential benefit of their work to people who need medical implants worldwide.

Information about the award and submission forms are available at URL http:/ /www.iumrs.org.

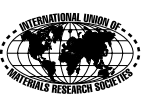

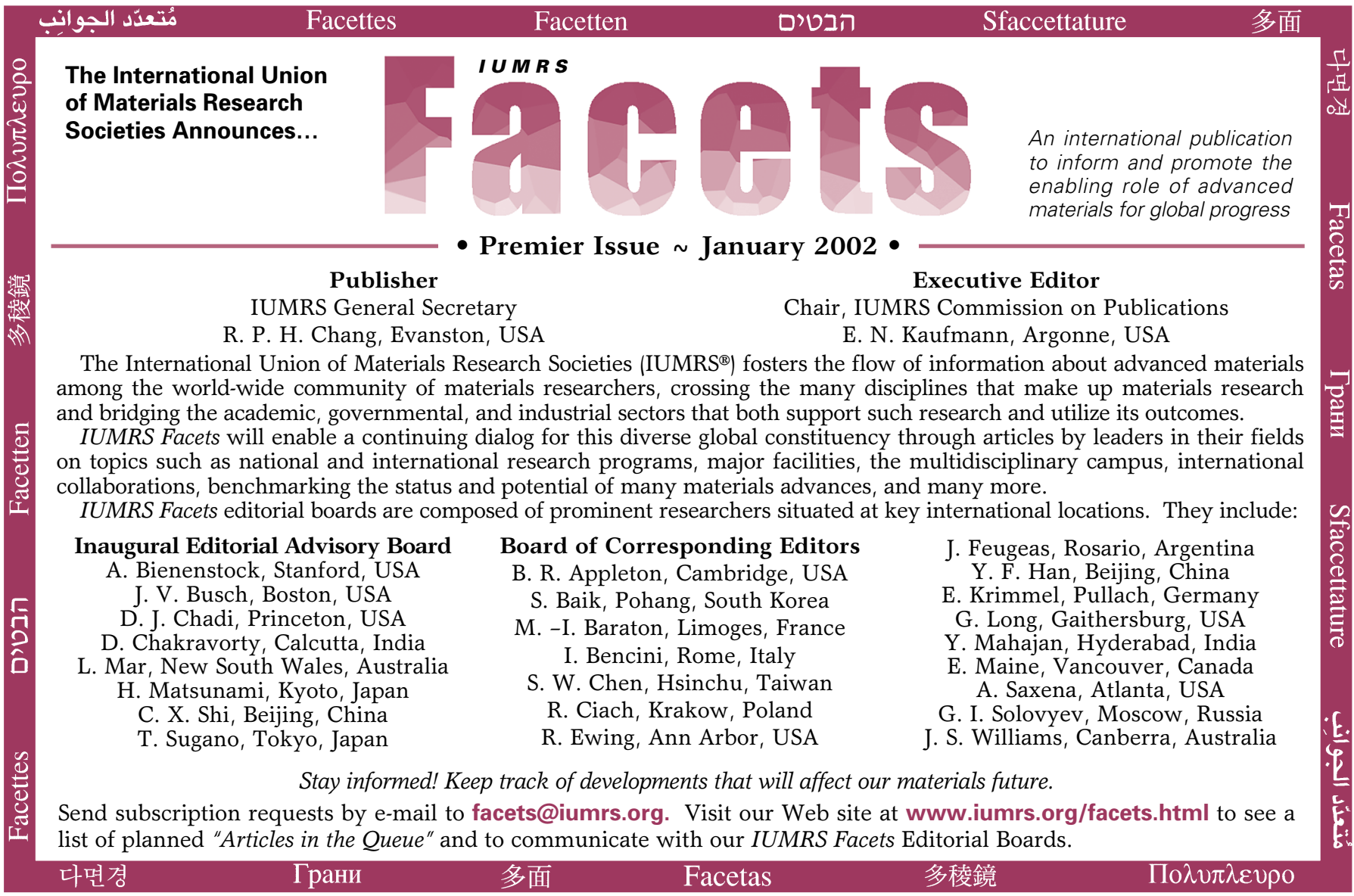

